\title{
Effect of Plastic Deformation on the Structure and Properties of the Ti/TiB Composite Produced by Spark Plasma Sintering
}

\author{
M. S. Ozerov ${ }^{a}$ *, M. Yu. Gazizova ${ }^{a}$, M. V. Klimova ${ }^{a}$, N. D. Stepanov ${ }^{a}$, and S. V. Zherebtsov ${ }^{a}$ \\ ${ }^{a}$ Belgorod State University, Belgorod, 308015 Russia \\ *e-mail: ozerov@bsu.edu.ru \\ Received September 6, 2017
}

\begin{abstract}
A Ti/17 vol \% TiB composite material is produced by spark plasma sintering of a mixture of titanium and $10 \mathrm{wt} \% \mathrm{TiB}_{2}$ powders at a temperature of $1000^{\circ} \mathrm{C}$. Multiaxial isothermal forging is performed at $t=850^{\circ} \mathrm{C}$ to enhance the mechanical properties of the composite. Deformation develops dynamic recrystallization in the titanium matrix and shortens $\mathrm{TiB}$ whisker crystals by a factor of $\sim 3$. Multiaxial isothermal deformation decreases the temperature of the brittle-to-ductile transition of the Ti/TiB composite material by $\sim 200^{\circ} \mathrm{C}$ (from $\sim 500$ to $\sim 300^{\circ} \mathrm{C}$ ) and results in a plasticity of $\sim 5 \%$ upon compression at room temperature. Deformation decreases the microhardness and the wear resistance to a certain degree. Multiaxial isothermal deformation weakly changes the corrosion properties of the composite material in comparison with the initial state.
\end{abstract}

Keywords: composite material, titanium, titanium boride, microstructure, deformation, forging, mechanical properties, brittle-to-ductile transition, wear, corrosion

DOI: $10.1134 / \mathrm{S} 003602951807008 \mathrm{X}$

\section{INTRODUCTION}

Titanium and titanium alloys are in great demand in various branches of engineering and medicine because of their low density, high specific strength, corrosion resistance, and biocompatibility [1]. However, titanium and low-alloy titanium alloys have an insufficiently high absolute strength, hardness, and wear resistance.

The strengthening of titanium can be achieved by creating titanium matrix composites by adding highhard titanium compounds, such as $\mathrm{TiB}, \mathrm{TiC}$, and $\mathrm{TiN}$ [2-5], as reinforcing components. Among them, TiB has a high stability at synthesizing temperatures and good crystallographic matching with a titanium matrix, thus ensuring minimum residual stresses $[6,7]$. Its density and thermal expansion coefficient are close to those of titanium. Spark plasma sintering (SPS) is one of the promising techniques to produce composite materials. Strong TiB whiskers form in a titanium matrix as a result of the chemical reaction $\mathrm{Ti}+\mathrm{TiB}_{2}=2 \mathrm{TiB}$ during SPS of a Ti/TiB composite material $[7,8]$. This technique provides low-temperature SPS for a short time, which, on the one hand, ensures a high efficiency of the technique even at almost $100 \%$ density of workpieces. On the other hand, it does not cause significant growth of structural elements, providing the formation of a nanostructured composite [9].
However, SPS-prepared Ti/TiB composites, despite the high strength owing to a TiB strengthening phase, have a low plasticity, especially at low temperatures $[7,10]$. Thermomechanical treatment is a possible way to increase the plasticity of $\mathrm{Ti} / \mathrm{TiB}$ composites. For example, the mechanical properties of $\mathrm{Ti} / \mathrm{TiB}$ composites were noticeably enhanced by deformation at the $\beta$-phase temperatures $[11,12]$. The choice of this treatment is advisable, since the titanium matrix in the region of $\beta$-phase existence exhibits an extremely high plasticity, which provides deformability of the composite material. However, high-temperature treatment of titanium alloys is usually associated with a number of processing problems, including those that require controlling the coarsening of a structure. Therefore, the problem of thermomechanical treatment of this composite material in the $\alpha$-phase region with low temperatures is very important. Unfortunately, there is little available information to determine the thermomechanical treatment parameters for this material and the possible level of mechanical (strength, plasticity, and hardness) and service (wear and corrosion resistance) properties. The aim of this work is to study the effect of plastic deformation performed in the $\alpha$ region on the structure and the properties of the SPS Ti/TiB composite material. 


\section{EXPERIMENTAL}

The Ti/TiB composite was prepared from a titanium powder $(99.1 \% \mathrm{Ti})$ with an average particle size of $25 \pm 10 \mu \mathrm{m}$ and titanium diboride $\left(99.9 \% \mathrm{TiB}_{2}\right)$ with an average particle size of $4 \pm 1.5 \mu \mathrm{m}$. The mass fraction of $\mathrm{TiB}_{2}$ in the initial mixture was $10 \%$, which corresponded to $17 \mathrm{vol} \% \mathrm{TiB}$ after synthesis [13]. The selected amount of reinforcing component provides a near-maximum strengthening effect. However, a further increase in the fraction of $\mathrm{TiB}_{2}$ weakly increases the strength but sharply decreases the ductility [7].

The powders were mixed in a Retsch RS200 vibrating disk mill for $1 \mathrm{~h}$ in ethanol at a milling rotation speed of $700 \mathrm{~min}^{-1}$. To prevent heating of the mixture during mixing, the milling pot was cooled with liquid nitrogen.

SPS at $1000^{\circ} \mathrm{C}$ and $40 \mathrm{MPa}$ for 5 min was carried out in a Thermal Technology SPS10-3 machine. The dimensions of workpieces were $\varnothing 19 \times 15 \mathrm{~mm}$. The temperature of the polymorphic $\alpha \rightleftarrows \beta$ transformation in the titanium matrix was $\sim 915^{\circ} \mathrm{C}$.

Samples $\varnothing 7 \times 10 \mathrm{~mm}$ in size were cut from composite workpieces using a Sodick AQ300L electricdischarge machine. Isothermal compression of samples to a strain of $70 \%$ (true strain of 1.2 ) was conducted at temperatures of 500,700 , and $850^{\circ} \mathrm{C}$ ( $\alpha$ phase range) and 950,1000 , and $1050^{\circ} \mathrm{C}(\beta$ phase range) at an initial strain rate of $10^{-3} \mathrm{~s}^{-1}$. Compression tests were carried out in air using an Instron 300LX testing machine equipped with a furnace for heating to $1200^{\circ} \mathrm{C}$. The heating time before deformation was $15 \mathrm{~min}$.

Prismatic-shaped samples $16 \times 14 \times 12 \mathrm{~mm}$ in size were cut to carry out multiaxial isothermal forging (MAF, the technique is also known as "abc deformation" [14]). MAF includes sequential compression of a prismatic sample along three orthogonal directions $a, b, c$. MAF was performed in air at $850^{\circ} \mathrm{C}$ using the Instron 300LX testing machine. The initial strain rate and the true strain of each MAF stage were $10^{-3} \mathrm{~s}^{-1}$ and $\sim 0.52$, respectively. There were 10 stages (compressions) at a total true strain $\Sigma \varepsilon=5.2$. Before each compression, the prismatic shape of the workpiece was restored by removing the curved surfaces using the electric-discharge machine.

X-ray diffraction (XRD) analysis was performed using an ARL-Xtra diffractometer and $\mathrm{CuK \alpha}$ radiation. Quantitative XRD analysis was performed using the Rietveld method [15] and the PowderCell software. The microstructure in axial section was examined by a Quanta 600 FEG scanning electron microscope (SEM) at an accelerating voltage of $30 \mathrm{kV}$ and a JEOL JEM-2100 transmission electron microscope (TEM) at an accelerating voltage of $200 \mathrm{kV}$. The porosity of the workpieces after SPS was determined by metallographic analysis and hydrostatic weighing.
The flat tensile samples had a gauge length of $4 \mathrm{~mm}$ and a gauge cross-section of $1.5 \times 3 \mathrm{~mm}$. Before testing, the samples were thoroughly grounded and polished. Deformation was carried out using an Instron 5882 universal testing machine at room and elevated $\left(300-700^{\circ} \mathrm{C}\right)$ temperatures and initial strain rate of $10^{-3} \mathrm{~s}^{-1}$. The Rockwell hardness was measured at a load of $1.48 \mathrm{kN}$ (150 kgf) for $5 \mathrm{~s}$. Ten measurements were performed in each state of a sample. The hardness of pure titanium after SPS was measured for comparison. The impact toughness was measured on samples with a V-shaped notch and dimensions of $55 \times 10 \times 2.5 \mathrm{~mm}$, according to Russian Standard GOST 9454-78 using a pendulum impact testing machine. To find the crack resistance of the composite material, we measured the length of cracks formed at the vertices of a rectangular indentation during measuring the Vickers microhardness, and then we calculated stresses $K_{\mathrm{s}}$ at the crack tip from formula $K_{\mathrm{s}}=x(E / H)^{0.5}\left(P / c^{3 / 2}\right)$, where $x$ is the empirical constant as a function of the geometry of the indenter (0.016 in our case), $E$ is the Young's modulus, $H$ is the hardness, $P$ is the load on the indenter, and $c$ is the crack length [16].

The tribological properties of the Ti/TiB composite in different states were measured under dry friction conditions in air using a ball-disk scheme (ASTM G99-959 and DIN 50324) using an automated TRIBOMETR CSM Instruments friction machine. Continuous measurement of the friction coefficient with an accuracy of \pm 0.001 was carried out directly during a test. A corundum ball with a diameter of $6 \mathrm{~mm}$ was used as a counterbody. The following conditions of tribological tests were used. The load on the holder of the counterbody was $5 \mathrm{~N}$. The speed of the ball was $5 \mathrm{~cm} / \mathrm{s}$. The radius of a friction track was $1.53 \mathrm{~mm}$ and the friction path was $500 \mathrm{~m}$. The wear resistance of a sample was determined from the wear factor. For this purpose, the cross-sectional area of a wear track was measured in five regions at three points with an accuracy of $\pm 0.01 \mu \mathrm{m}$ using a Sutronic 25 contact precision profilometer. A FEI Quanta 200 3D scanning electron microscope was used to examine the morphology of a friction track.

The corrosion resistance was determined by the electrochemical method using an IPC-Pro potentiostat and a standard three-electrode cell in Ringer solution ( $0.9 \%$ aqueous $\mathrm{NaCl}$ solution) at room temperature. Chloride silver and carbon electrodes were used as a reference electrode and an auxiliary electrode, respectively. Before anodic polarization, each sample was soaked in test solution for at least $1 \mathrm{~h}$; the change in the stationary potential $E_{\mathrm{st}}$ for $30 \mathrm{~min}$ did not exceed $30 \mathrm{mV}$. Anodic polarization was conducted from reached stationary potential $E_{\mathrm{st}}$ to $3 \mathrm{~V}$ at a scanning rate of $1 \mathrm{mV} / \mathrm{s}$. Samples after tests were washed in distilled water and air dried. 

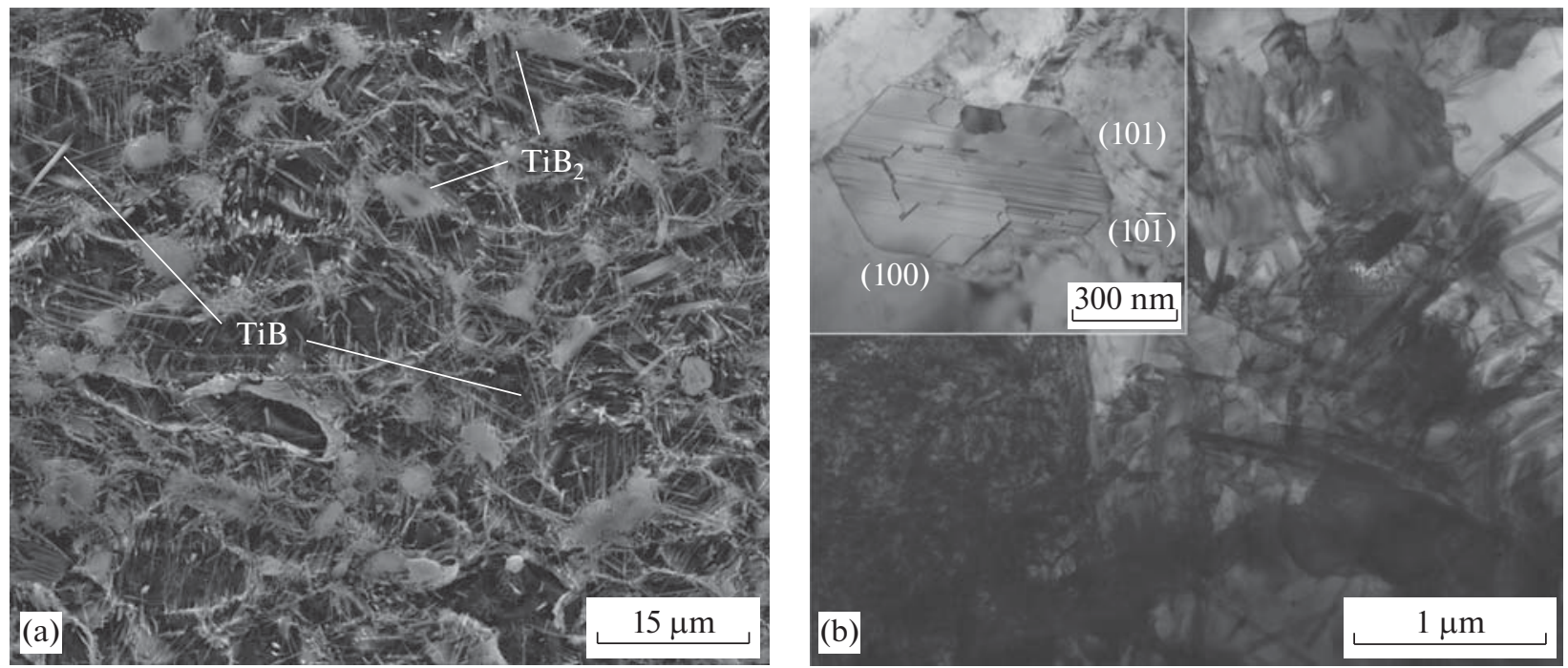

Fig. 1. Microstructure of the Ti/TiB composite material after SPS: (a) SEM and (b) TEM (inset shows the cross section of TiB crystal).
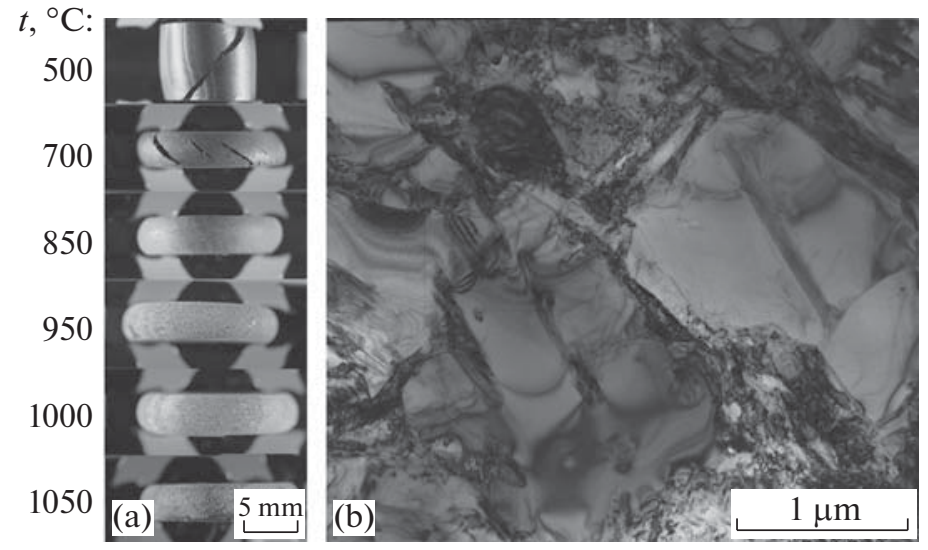

Fig. 2. (a) Appearance of $\mathrm{Ti} / \mathrm{TiB}$ samples upon compression at $500-1050^{\circ} \mathrm{C}$ and (b) microstructure (TEM) of the composite material after $70 \%$ deformation at $850^{\circ} \mathrm{C}$.

The tribological and corrosion properties of the composite material were compared with those of commercial-purity VT1-0 titanium samples cut from a hot-rolled bar $40 \mathrm{~mm}$ in diameter. The grain size in the initial state was $\sim 30 \mu \mathrm{m}$.

\section{RESULTS AND DISCUSSION}

The microstructure of the Ti/TiB composite material produced by SPS in the initial state consists of titanium boride whiskers nonuniformly distributed in the titanium matrix and unreacted titanium diboride particles (Fig. 1a). TEM also showed a nonuniform composite structure (Fig. 1b). There are individual TiB crystals in some regions with a low dislocation density. However, the most part of volume has a high dislocation density, which, apparently, caused by the great number of TiB particles in the structure. TiB whiskers in the cross section have the shape of an irregular hexagon bounded by (100), (10) $)$, and (101) planes [17] (inset to Fig. 1b). A large number of stacking faults parallel to the (100) plane are observed in TiB crystals. The cross-sectional size of TiB whiskers was $63 \pm$ $35 \mathrm{~nm}$, and the ratio of whisker length to cross-section (diameter) was $\sim 47$. According to XRD analysis, the volume fraction of titanium, $\mathrm{TiB}$, and $\mathrm{TiB}_{2}$ in the composite structure is $78.6,19$, and $2.4 \%$, respectively. The volume fraction of pores in the structure is $0.5 \%$.

Compression tests in the temperature range 500$1050^{\circ} \mathrm{C}$ showed good deformability of the composite material at $850^{\circ} \mathrm{C}$ or above (Fig. 2a). Surface cracks appear at a compressing temperature of $700^{\circ} \mathrm{C}$ and the sample fails at $500^{\circ} \mathrm{C}$ along the plane of application of 
the highest tangential stresses. Deformation at $850^{\circ} \mathrm{C}$ results in dynamic recrystallization in the titanium matrix and the formation of new grains $\sim 1 \mu \mathrm{m}$ in size, the boundaries of which have a fairly perfect structure with a typical banded contrast (Fig. 2b). The formation of new grains is more typical for regions with a small number of TiB crystals. Regions with a large number of TiB crystals prevent the grain growth and retain the deformed microstructure.

Based on the results of compression tests, we subjected $\mathrm{Ti} / \mathrm{TiB}$ composite samples to $\mathrm{MAF}$ at $850^{\circ} \mathrm{C}$ to increase the plastic properties of the composite material. MAF shortened TiB whisker crystals by a factor of $\sim 3$ (Figs. 3a, 3c). However, the diameter of the TiB whiskers remains practically the same, and the stable length-to-transverse size ratio is still $\sim 10$. TEM study showed that the deformation at $850^{\circ} \mathrm{C}$ to $\Sigma \varepsilon=5.2$ (10 steps) resulted in the formation of a partially recrystallized structure with grains $1.0-1.5 \mu \mathrm{m}$ in size (Fig. 3b).

Thermomechanical treatment significantly changes the mechanical properties of the $\mathrm{Ti} / \mathrm{TiB}$ composite. The composite material after MAF at $850^{\circ} \mathrm{C}$ (total strain of 5.2) showed a plasticity of $\sim 5 \%$ during compression at room temperature, whereas the initial composite material failed in the elastic region (Fig. 4a). The compressive strengths of the initial and forged samples are rather close, 2210 and $1960 \mathrm{MPa}$ at room temperature, respectively. The impact toughness of the MAF-deformed sample is higher by $30 \%$ (Table 1 ) and the cracking resistance is higher by a factor of $\sim 2$ as compared to those of the initial state after sintering. The MAF-induced increase in the plasticity also manifests itself in a temperature shift of the brittle-to-ductile transition of the $\mathrm{Ti} / \mathrm{TiB}$ composite material from $\sim 500$ to $\sim 300^{\circ} \mathrm{C}$, which is clearly visible from the tensile test results (Fig. 4b). In this case, some decrease in strength is observed. For example, the strength properties of the initial composite at $500^{\circ} \mathrm{C}$ are almost the same that those at $400^{\circ} \mathrm{C}$ after MAF. Recrystallization of the titanium matrix and refinement of TiB whiskers and their more uniform distribution in the titanium matrix after MAF at $850^{\circ} \mathrm{C}$ seem to be responsible for the increased plastic properties and the slightly decreased strength.

The smaller (by $\sim 17 \%$ ) hardness indicates a slight decrease in the strength of the composite after MAF (Table 2). However, in comparison with commercialpurity titanium, the hardness of the composite in both states is more than 2 times higher. However, the tribological properties do not become better due to the increased hardness of the composite. Table 2 suggests that the hardening of titanium with $\mathrm{TiB}$ whiskers increases the friction coefficient by $\sim 30 \%$. MAF somewhat reduces the friction coefficient (from 0.71 to 0.66). The wear factor of the composite also increases by a factor of about two as compared to pure titanium, and the difference increases after MAF.
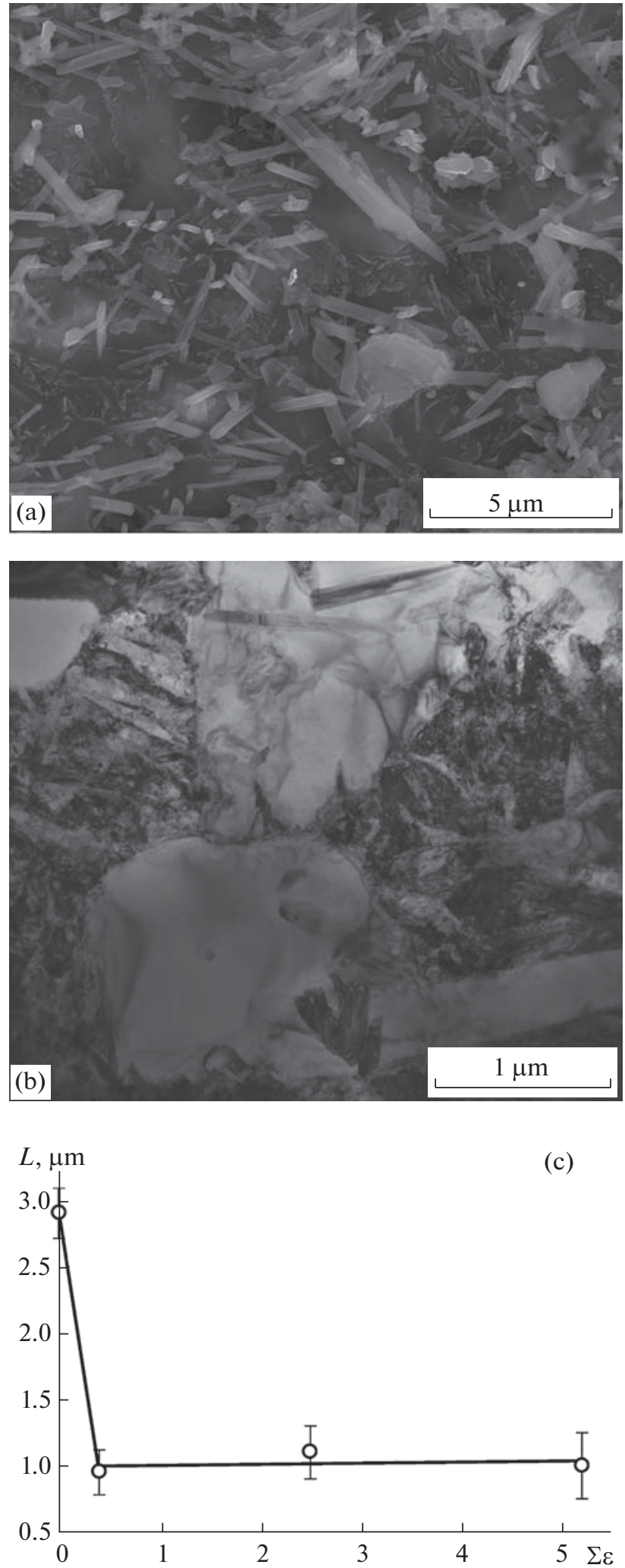

Fig. 3. Microstructure of the $\mathrm{Ti} / \mathrm{TiB}$ composite material deformed by $\mathrm{MAF}$ at $850^{\circ} \mathrm{C}$ to a total strain of $\sim 5.2$ (a) SEM, (b) TEM) and (c) length $L$ of TiB crystals as a function of the MAF srain. 

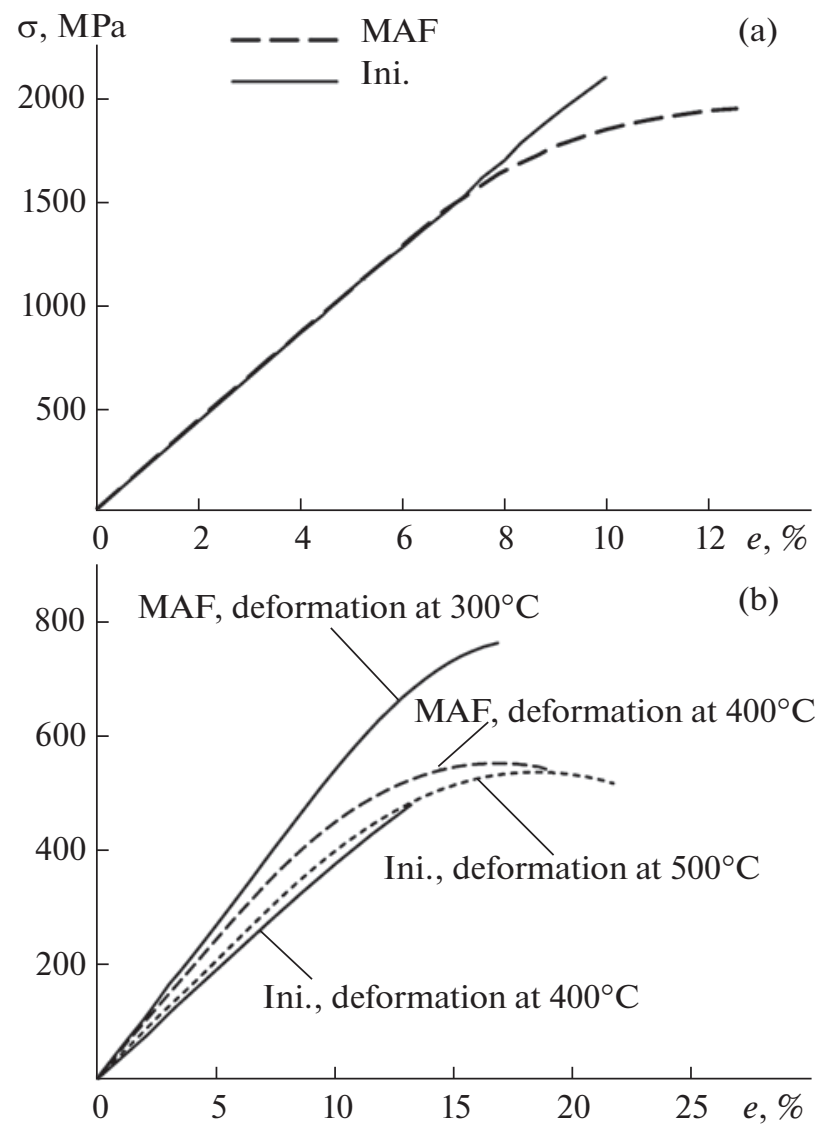

Fig. 4. Stress-strain curves of the Ti/TiB composite material in the initial state (Ini.) and after MAF: (a) uniaxial compression at room temperature and (b) tension at 300 , 400 , and $500^{\circ} \mathrm{C}$.

The decrease in the wear resistance of the composite in comparison with commercial-purity VT1-0 titanium is probably related to the spalling of hard $\mathrm{TiB}$ whiskers, which then work as an abrasive in the places of frictional contact. Since the average transverse size

Table 1. Impact toughness and crack resistance of the $\mathrm{Ti} / \mathrm{TiB}$ composite material in the initial state (numerator) and after MAF (denominator)

\begin{tabular}{c|c}
\hline$K C V, \mathrm{~J} / \mathrm{cm}^{2}$ & $K_{\mathrm{s}}, \mathrm{MPa} \mathrm{m}{ }^{1 / 2}$ \\
\hline$\frac{0.8790}{1.2149}$ & $\frac{4}{8}$ \\
\hline
\end{tabular}
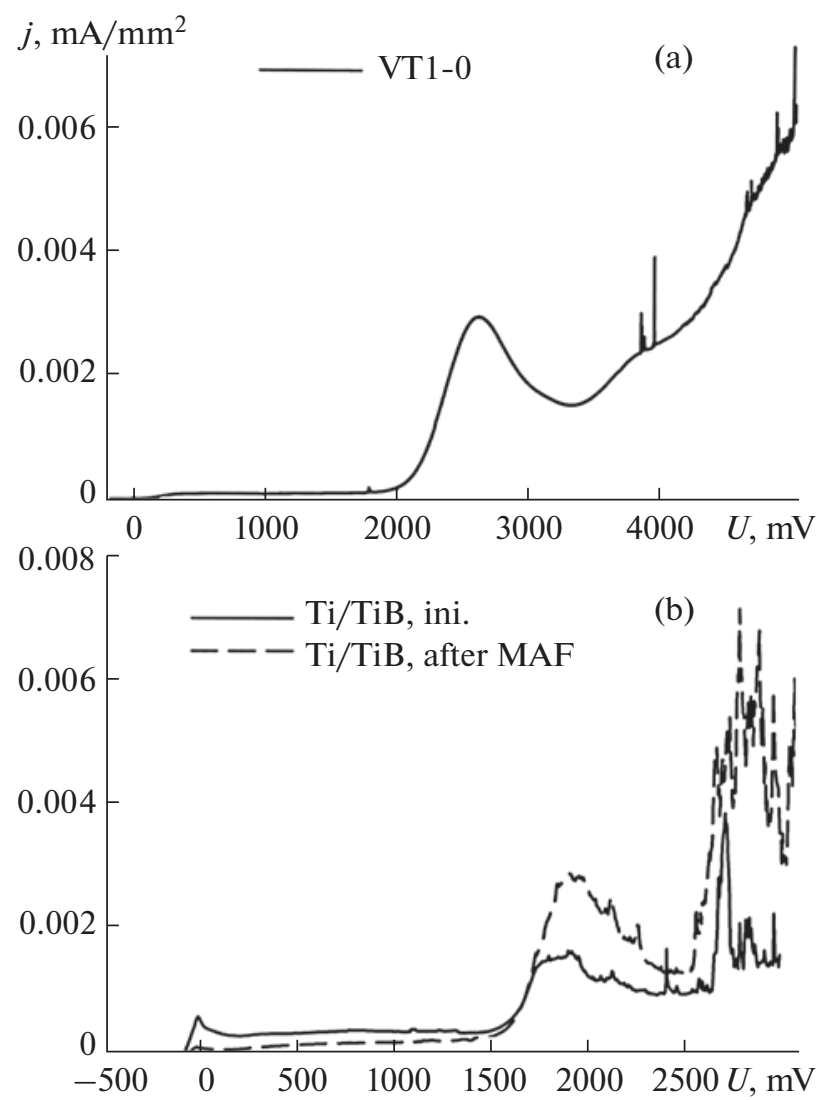

Fig. 5. Anodic polarization curves $(j$ is the current density, $U$ is the potential) for (a) commercial purity VT1-0 titanium and (b) $\mathrm{Ti} / \mathrm{TiB}$ composite material in the initial state and after MAF.

of TiB crystals is $<100 \mathrm{~nm}$, spalling proceeds much easier than that in the case of micrometer TiB hardeners [18]. Therefore, the wear resistance of Ti/TiB composites with coarse $\mathrm{TiB}$ precipitates exceeds that of pure titanium. Thus, the decrease in the wear resistance of the composite can be explained by a change in the wear mechanism from adhesion in the case of VT1-0 titanium to abrasive for the Ti/TiB composite. The plastic-deformation-induced fracture of $\mathrm{TiB}$ crystals during MAF seems to cause even more intense wear. A similar change in a wear mechanism was observed for a $\mathrm{Ti} /(\mathrm{TiN}+\mathrm{TiB})$ composite in [19].

The study of the electrochemical corrosion of $\mathrm{Ti} / \mathrm{TiB}$ composites suggests that the introduction of

Table 2. Tribological properties of $\mathrm{Ti} / \mathrm{TiB}$ samples (initial state and after $\mathrm{MAF}$ at $850^{\circ} \mathrm{C}$ ) in comparison with commercialpurity VT1-0 titanium

\begin{tabular}{l|c|c|c}
\hline \multicolumn{1}{c|}{ Sample } & $\begin{array}{c}\text { Hardness } \\
\text { HRC }\end{array}$ & $\begin{array}{c}\text { Friction } \\
\text { coefficient } \mu\end{array}$ & $\begin{array}{c}\text { Wear factor, } \\
\mathrm{mm}^{3} \mathrm{~N}^{-1} \mathrm{~m}^{-1}\left(\times 10^{-4}\right)\end{array}$ \\
\hline VT1-0 & $29 \pm 3$ & 0.55 & 4.25 \\
Ti/TiB, initial & $48 \pm 4$ & 0.71 & 7.09 \\
Ti/TiB, after MAF & $40 \pm 3$ & 0.66 & 8.30 \\
\hline
\end{tabular}


Table 3. Stationary potential $E_{\mathrm{st}}(\mathrm{mV})$ of the Ti/TiB composite material in the initial state and after MAF at $850^{\circ} \mathrm{C}$ in comparison with commercial-purity VT1-0 titanium

\begin{tabular}{c|c|c}
\hline VT1-0 titanium & Ti/TiB, initial & Ti/TiB, after MAF \\
\hline-309 & -212 & -244 \\
\hline
\end{tabular}

reinforcing agents $(\mathrm{TiB})$ into the titanium matrix changes corrosion properties. The stationary potential $E_{\text {st }}$ of the composite in both states is higher than that of the commercial-purity VT1-0 titanium, which indicates an increase in the corrosion resistance under our conditions (Table 3). Nevertheless, it should be noted that the stationary potential for the composite after MAF is more negative than that of the initial state, which indicates the deterioration of its corrosion resistance.

Figure 5 shows the anode polarization curves of pure titanium and the Ti/TiB composite. As can be seen from the curves, the corrosion potential of pure titanium corresponds to $\sim 2050 \mathrm{mV}$ (Fig. 5a), whereas this value for both states of the composite is $\sim 1550 \mathrm{mV}$ (Fig. 5b). The passivation of commercial-purity titanium and the $\mathrm{Ti} / \mathrm{TiB}$ composite begins at polarization potentials of 2600 and $1850-1870 \mathrm{mV}$, respectively. Complete passivation of titanium takes place at a potential of $3280 \mathrm{mV}$, and that of a composite, at $2400 \mathrm{mV}$. Comparable current densities, corresponding to the passivation onset of pure titanium and the composite, should be noted. MAF somehow worsens the corrosion properties of the composite (Fig. 5b), but both states of the composite in the region of small potentials (up to the corrosion potential) have comparable properties that are as good as those of pure titanium. The data obtained are in agreement with the results of recent works [20,21], which also shows comparable corrosion properties of the $\mathrm{Ti} / \mathrm{TiB}$ composite material and commercial-purity titanium.

\section{CONCLUSIONS}

(1) Uniaxial compression in the temperature range $500-1050^{\circ} \mathrm{C}$ showed that thermomechanical treatment of the $\mathrm{Ti} / \mathrm{TiB}$ composite can be carried out at temperatures above $700^{\circ} \mathrm{C}$. MAF of the $\mathrm{Ti} / \mathrm{TiB}$ composite material at $850^{\circ} \mathrm{C}$ reduces the length of $\mathrm{TiB}$ whiskers by a factor of $\sim 3$, causes the development of dynamic recrystallization upon deformation, and form grains $1.0-1.5 \mu \mathrm{m}$ in size.

(2) MAF to a total strain of $\sim 5.2$ at $850^{\circ} \mathrm{C}$ significantly decreases the brittle-to-ductile transition temperature (from $\sim 500$ to $\sim 300^{\circ} \mathrm{C}$ ) of the $\mathrm{Ti} / \mathrm{TiB}$ composite material, provides a plasticity of $\sim 5 \%$ upon compression at room temperature without a significant decrease in the strength, and increases the crack resistance by a factor of 2 and the impact strength by $30 \%$.

(3) The hardness of the composites is $40-60 \%$ higher than that of commercial-purity VT1-0 titanium. The hardness of the composite after MAF decreased by $\sim 17 \%$. Wear tests showed an increase in the friction coefficient of the Ti/TiB composite material from 0.55 to 0.71 as compared to that of pure titanium. MAF weakly changed the tribological properties.

(4) The study of electrochemical corrosion demonstrated comparable properties of the composite material and pure titanium.

\section{ACKNOWLEDGMENTS}

This work was supported by the Russian Science Foundation, project no. 15-19-00165.

\section{REFERENCES}

1. C. Leyens and M. Peters, Titanium and Titanium Alloys. Fundamentals and Applications (Wiley-VCH, Weinheim, 2003).

2. T. M. T. Godfrey, P. S. Goodwin, and C. M. WardClose, "Titanium particulate metal matrix composites-reinforcement, production methods, and mechanical properties," Adv. Eng. Mater. 2, 85-91 (2000).

3. V. K. Lindroos and M. J. J. Talvitie, "Recent advances in metal matrix composites," Mater. Proc. Technol. 53, 273-284 (1995).

4. T. Saito, T. Furuta, and T. Yamaguchi, "Development of low cost titanium matrix composite," in Advances in Titanium Metal Matrix Composites (Minerals, Metals and Materials Society, 1996), pp. 33-44.

5. B. V. Radhakrishna Bhat, J. Subramanyam, and V. V. Bhanu Prasad, "Preparation of Ti-TiB-TiC \& Ti-TiB composites by in situ reaction hot pressing," Mater. Sci. Eng. A 325, 126-130 (2002).

6. M. Ozerov, M. Klimova, A. Vyazmin, N. Stepanov, and S. Zherebtsov, "Orientation relationship in a Ti/TiB metal-matrix composite," Mater. Lett. 186, 168-170 (2017).

7. K. Morsi and V. V. Patel, "Processing and properties of titanium-titanium boride $\left(\mathrm{TiB}_{\mathrm{w}}\right)$ matrix composites: a review," Mater. Sci. 42, 2037-2047 (2007).

8. H. Feng, Yu Zhou, D. Jia, Q. Meng, and J. Rao, "Growth mechanism of in situ TiB whiskers in spark plasma sintered TiB/Ti metal matrix composites," Cryst. Growth Des. 7, 1626-1630 (2006).

9. A. V. Ragulya, "Fundamentals of spark plasma sintering," in Science and Technology, Ed. by K. H. Jürgen Buschow et al. (Encyclopedia of Materials, 2010), pp. 1-5.

10. M. Ozerov, N. Stepanov, A. Kolesnikov, V. Sokolovsky, and S. Zherebtsov, "Brittle-to-ductile transition in a Ti-TiB metal-matrix composite," Mater. Lett. 187, 28-31 (2017).

11. R. A. Gaisin, V. M. Imayev, and R. M. Imayev, "Effect of hot forging on microstructure and mechanical prop- 
erties of near a titanium alloy/TiB composites produced by casting," J. Alloys Compd. 723, 385-394 (2017).

12. V. Imayev, R. Gaisin, E. Gaisina, R. Imayev, H.-J. Fecht, and F. Pyczak, "Effect of hot forging on microstructure and tensile properties of Ti-TiB," Mater. Sci. Eng. A 609, 34-41 (2014).

13. L. J. Huang, L. Geng, B. Wang, and L. Z. Wu, "Effects of volume fraction on the microstructure and tensile properties of in situ $\mathrm{TiB}_{\mathrm{w}} / \mathrm{Ti}_{6} \mathrm{Al}_{4} \mathrm{~V}$ composites with novel network microstructure," Mater. Design. 45, 532-538 (2013).

14. G. A. Salishchev, S. Yu. Mironov, and S. V. Zherebtsov, "Mechanisms of submicrocrystalline structure formation in titanium and two-phase titanium alloy during warm severe processing," Rev. Adv. Mater. Sci. 11, 152-158 (2006).

15. G. Will, Powder Diffraction: The Rietveld Method and the Two-Stage Method to Determine and Refine Crystal Structures from Powder Diffraction Data (Springer, Heidelberg, 2006).

16. G. M. Pharr, "Measurement of mechanical properties by ultra-low load indentation," Mater. Sci. Eng. A 263, 161-169 (1998).
17. M. Ozerov, M. Klimova, A. Kolesnikov, N. Stepanov, and S. Zherebtsov, "Deformation behavior and microstructure evolution of a Ti/TiB metal-matrix composite during high-temperature compression tests," Mater. Design. 112 , 17-26 (2016).

18. T. Yamamoto, A. Otsuki, K. Ishihara, and P. H. Shingu, "Synthesis of near net shape high density TiB/Ti composite,” Mater. Sci. Eng. A 293, 647-651 (1997).

19. R. Yazdi and S. F. Kashani-Bozorg, "Microstructure and wear of in situ $\mathrm{Ti} /(\mathrm{TiN}+\mathrm{TiB})$ hybrid composite layers produced using liquid phase process," Mater. Chem. Phys. 152, 147-157 (2015).

20. Y. Chen, J. Zhang, N. Dai, P. Qin, H. Attar, L.-C. Zhang, "Corrosion behaviour of selective laser melted Ti-TiB biocomposite in simulated body fluid," Electrochimica Acta 232, 89-97 (2017).

21. B. Sivakumar, R. Singh, L. C. Pathak, "Corrosion behavior of titanium boride composite coating fabricated on commercial-purity titanium in Ringer's solution for bioimplant applications," Mater. Sci. Eng. C 48, 243-255 (2015).

Translated by T. Gapontseva 